\title{
Ignition during hydrogen release from high pressure into the atmosphere
}

\author{
P. Oleszczak • P. Wolanski
}

Received: 3 November 2009 / Revised: 29 March 2010 / Accepted: 21 October 2010 / Published online: 12 November 2010

(C) The Author(s) 2010. This article is published with open access at Springerlink.com

\begin{abstract}
The first investigations concerned with a problem of hydrogen jet ignition, during outflow from a high-pressure vessel were carried out nearly 40 years ago by Wolanski and Wojcicki. The research resulted from a dramatic accident in the Chorzow Chemical Plant Azoty, where the explosion of a synthesis gas made up of a mixture composed of three moles of hydrogen per mole of nitrogen, at $300^{\circ} \mathrm{C}$ and $30 \mathrm{MPa}$ killed four people. Initial investigation had excluded potential external ignition sources and the main aim of the research was to determine the cause of ignition. Hydrogen is currently considered as a potential fuel for various vehicles such as cars, trucks, buses, etc. Crucial safety issues are of potential concern, associated with the storage of hydrogen at a very high pressure. Indeed, the evidence obtained nearly 40 years ago shows that sudden rupture of a highpressure hydrogen storage tank or other component can result in ignition and potentially explosion. The aim of the present research is identification of the conditions under which hydrogen ignition occurs as a result of compression and heating of the air by the shock wave generated by discharge of high-pressure hydrogen. Experiments have been conducted using a facility constructed in the Combustion Laboratory of the Institute of Heat Engineering, Warsaw University of Technology. Tests under various configurations have been
\end{abstract}

Communicated by L. Bauwens.

This paper is based on work that was presented at the 22nd International Colloquium on the Dynamics of Explosions and Reactive Systems, Minsk, Belarus, July 27-31, 2009.

P. Oleszczak $(\varangle) \cdot$ P. Wolanski

Institute of Heat Engineering, Warsaw University of Technology,

Warsaw, Poland

e-mail: polesz@itc.pw.edu.pl

P. Wolanski

e-mail: wolanski@itc.pw.edu.pl performed to determine critical conditions for occurrence of high-pressure hydrogen ignition. The results show that a critical pressure exists, leading to ignition, which depends mainly on the geometric configuration of the outflow system, such as tube diameter, and on the presence of obstacles.

Keywords Hydrogen $\cdot$ Safety $\cdot$ Ignition

\section{Introduction}

Hydrogen ignition caused by rupture of a high-pressure installation was first investigated nearly 40 years ago by Wolanski and Wojcicki [1-3]. That investigation followed from a tragic accident at the Chorzow chemical plant Azoty, where a synthesis gas consisting of a hydrogen-nitrogen mixture, $3 \mathrm{H} 2-\mathrm{N} 2$, at $300^{\circ} \mathrm{C}$ and $30 \mathrm{MPa}$ exploded, killing four people. An initial investigation had excluded potential external sources of the ignition, and the research aimed to determine the real ignition source. It was found that ignition actually occurred due to heating by the shock wave generated by the outflow of high-pressure synthesis gas. Mixing of hydrogen with the air heated up by the shock wave preceding the expanding hydrogen was found to result in ignition of mixed hydrogen and air. Recently, there have been several new reports on high-pressure hydrogen leaks causing ignition, in the absence of external ignition sources.

Numerous papers focusing upon hydrogen safety and concerned with high-pressure hydrogen jet ignition have been recently published, such as Golub et al. and Mogi et al. [4-9] who conducted experimental work, or numerical investigation [10-12].

Hydrogen is regarded as a potential fuel for various kinds of vehicles, such as cars, including fuel cell cars, trucks, buses, etc. High-pressure hydrogen storage and transportation entails crucial safety issues that will need to be addressed 
Fig. 1 Experimental setup
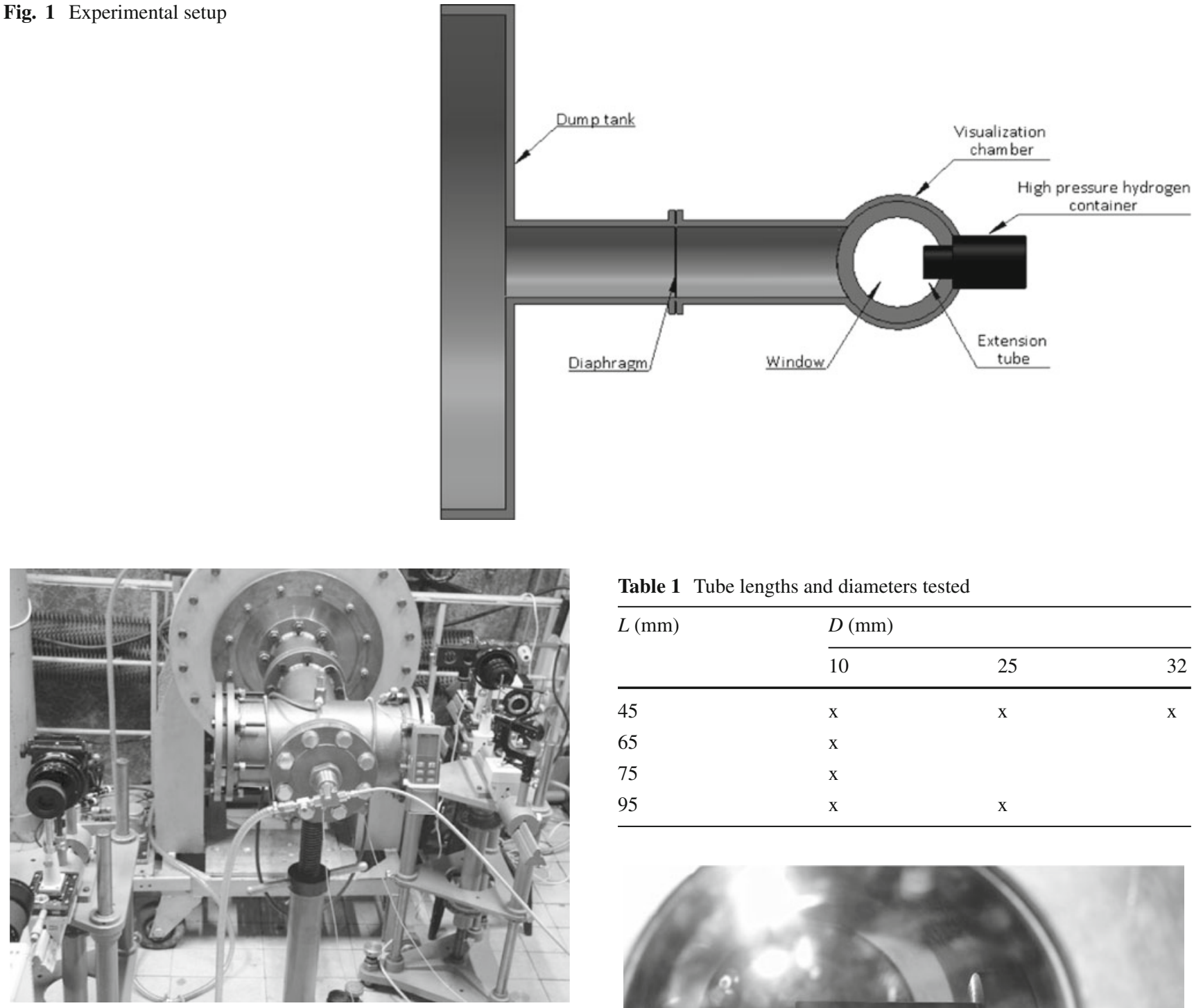

Table 1 Tube lengths and diameters tested

\begin{tabular}{|c|c|c|c|}
\hline \multirow[t]{2}{*}{$L(\mathrm{~mm})$} & \multicolumn{3}{|c|}{$D(\mathrm{~mm})$} \\
\hline & 10 & 25 & 32 \\
\hline 45 & $\mathrm{x}$ & $\mathrm{x}$ & $\mathrm{x}$ \\
\hline 65 & $\mathrm{x}$ & & \\
\hline 75 & $\mathrm{x}$ & & \\
\hline 95 & $\mathrm{x}$ & $\mathrm{x}$ & \\
\hline
\end{tabular}

Fig. 2 View of the experimental facility
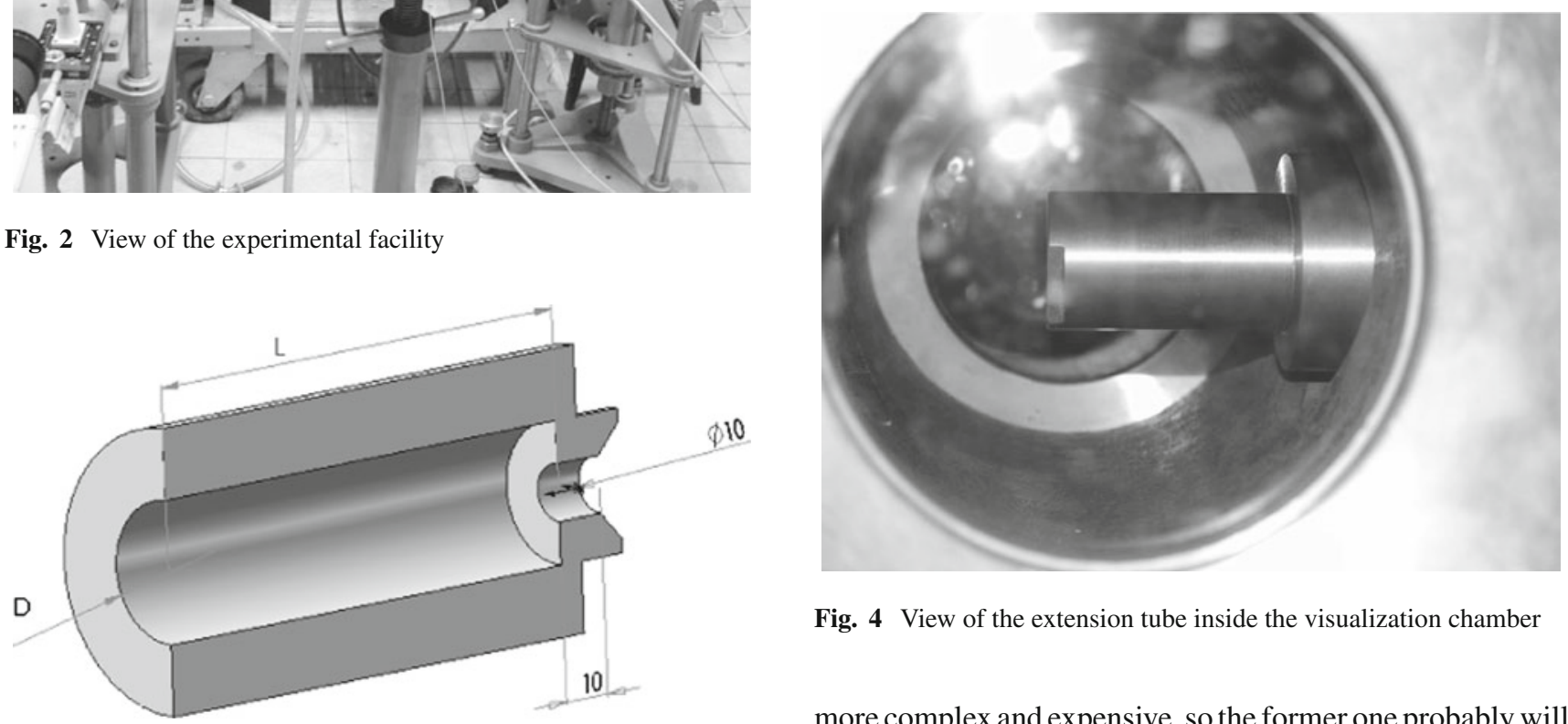

Fig. 4 View of the extension tube inside the visualization chamber

more complex and expensive, so the former one probably will be more common. Sudden rupture of high-pressure hydrogen storage components may result in ignition and potentially explosion. It is anticipated that pressure in vehicle hydrogen tanks may be of 35, 70 or even $100 \mathrm{MPa}$, which could result in a significant hazard due to sudden discharge of hydrogen, ignition and significant accidents. 

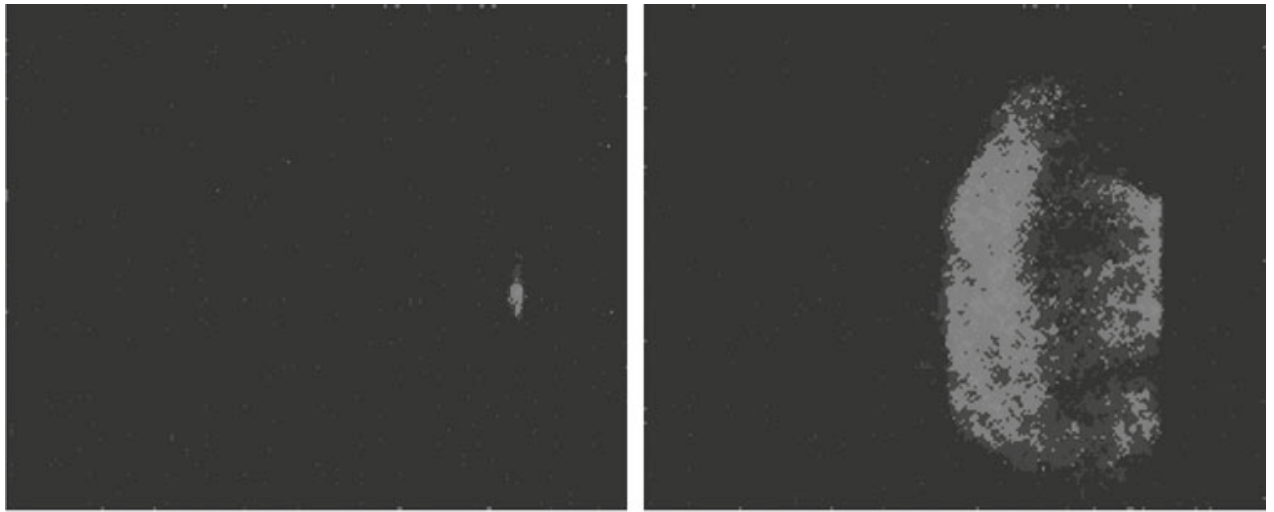

$T=0 \mathrm{~s}$

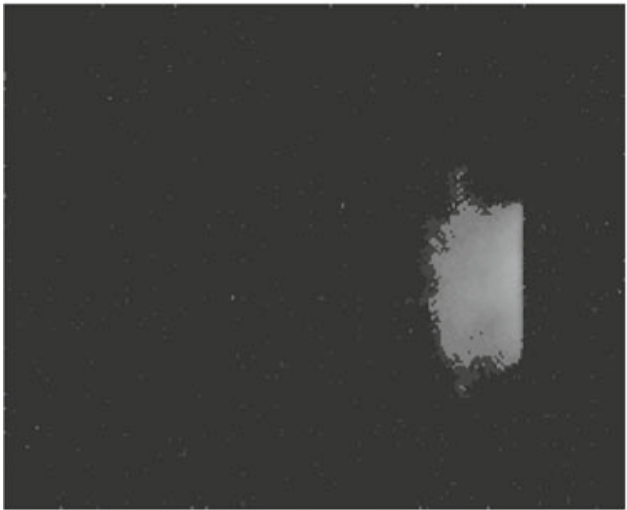

$\mathrm{T}=25 \mu \mathrm{s}$

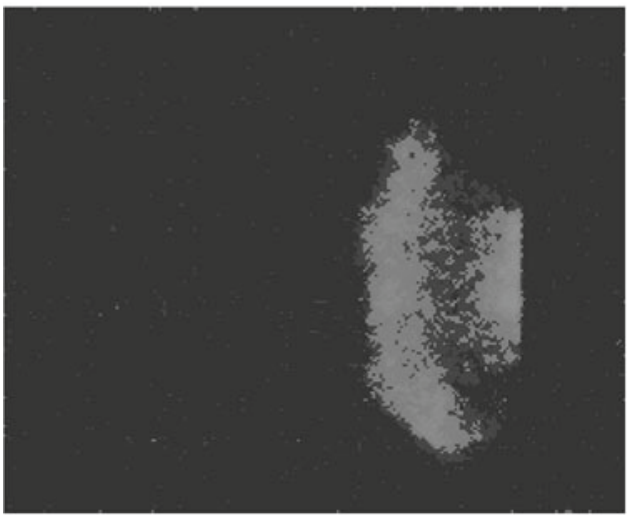

$\mathrm{T}=50 \mu \mathrm{s}$
$\mathrm{T}=75 \mu \mathrm{s}$

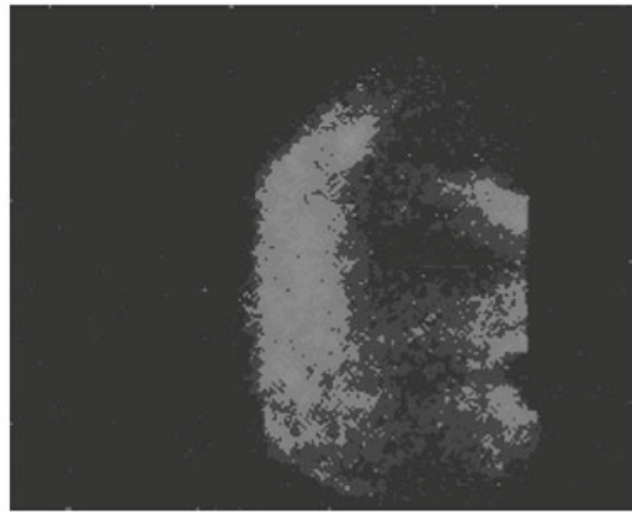

$\mathrm{T}=100 \mu \mathrm{s}$

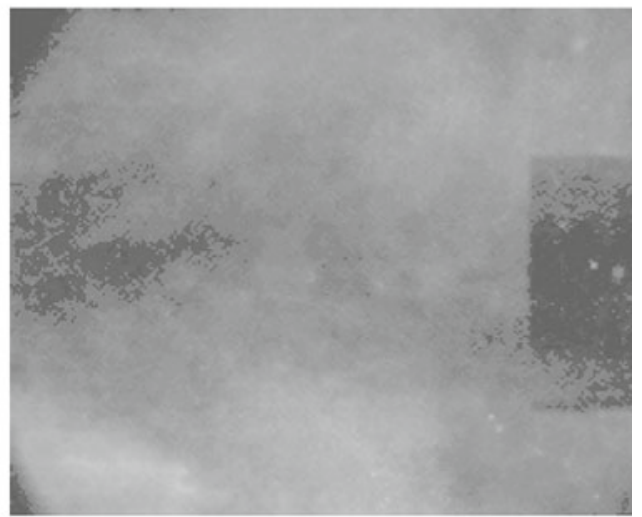

$\mathrm{T}=2.91 \mathrm{~ms}$

Fig. 5 Direct pictures of the hydrogen ignition, extension tube length $45 \mathrm{~mm}$, extension tube diameter $32 \mathrm{~mm}$, initial hydrogen pressure equal to 6.2 MPa. Frame rate 80,000 f/s, shutter $5.5 \mu \mathrm{s}$

The aim of the current research is to identify the conditions under which hydrogen ignition takes place as a result of air compression and heating by the shock wave generated by hydrogen discharge of the hydrogen and determination of the critical pressure needed for ignition. The critical pressure is found to depend mainly on the geometric configuration of the outflow system, including tube diameter, and the presence of obstacles.

\section{Experimental facility}

The experimental tests were conducted on a facility built in the Combustion Laboratory of the Institute of Heat Engineering, Warsaw University of Technology. A schematic description of the facility is presented in Fig. 1. Its main elements are a high-pressure hydrogen container and a visualization chamber. Both hydrogen container and visualization chamber are 


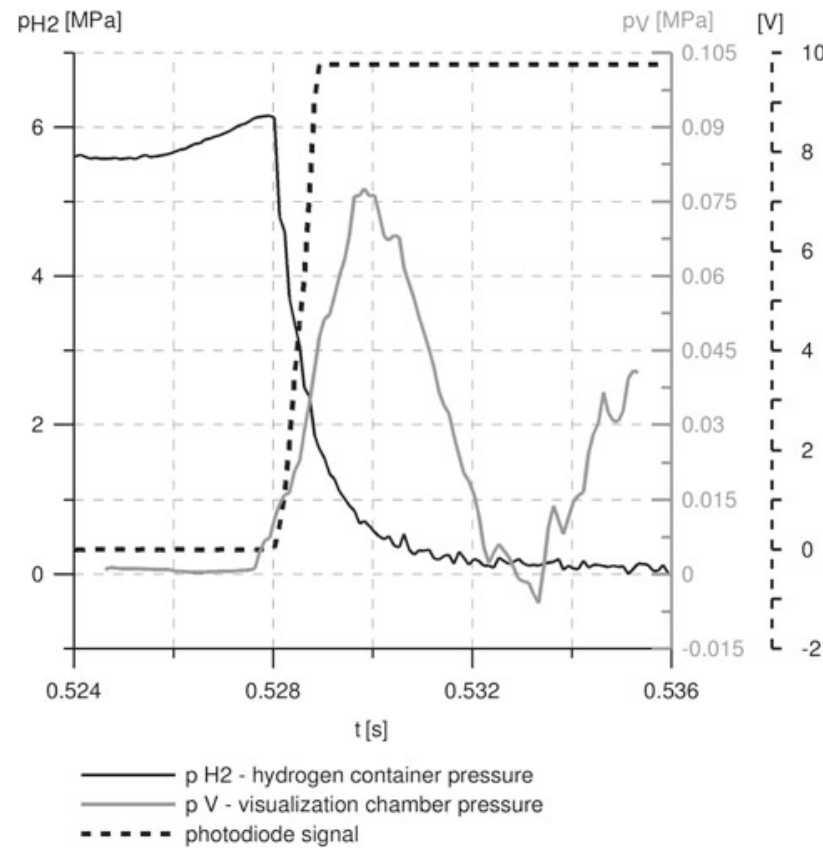

Fig. 6 Pressures and signal from photodiode courses. Extension tube length $45 \mathrm{~mm}$, extension tube diameter $32 \mathrm{~mm}$, initial hydrogen pressure equal to $6.2 \mathrm{MPa}$

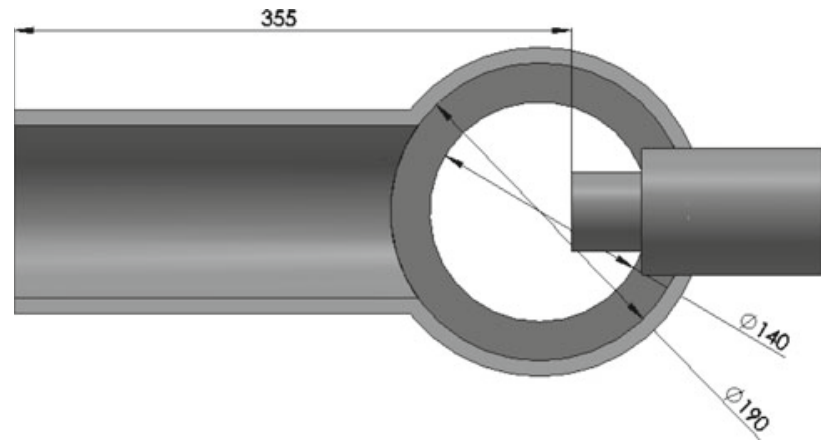

Fig. 7 Geometry of the facility. Extension tube length $45 \mathrm{~mm}$

equipped with pressure transducers. The visualization chamber is also equipped with a photodiode sensitive to the flame. A general view of the facility is shown in Fig. 2.

The high-pressure hydrogen container is closed by a plastic diaphragm which bursts when a predetermined pressure inside the container is reached. An extension tube can be attached to the container. Extension tubes of various geometries have been tested in experimental and numerical investigations [4-6]. The extension tube tested in the current research consists of two parts: a first one, with diameter 10 and $10 \mathrm{~mm}$ long, placed immediately behind the diaphragm, and a second one connected to the first one, with various diameters and lengths. A scheme of the extension tube is presented in Fig. 3. Lengths and diameters tested are listed in Table 1. A view of the high-pressure hydrogen container with the extension tube inside the visualization chamber is shown in Fig. 4.
The visualization chamber volume is separated from a dump tank by a second plastic diaphragm. For safety reasons, the initial pressure in the dump tank never exceeds $0.03 \mathrm{MPa}$ absolute. The plastic diaphragm placed between the visualization chamber and the dump tank bursts almost instantly after hydrogen outflow, and hydrogen, air and combustion products flow out from the visualization chamber. This limits the amount of hydrogen burned in the test, reduces the pressure rise inside the visualization chamber and lowers the noise generated by the shock wave and the hydrogen explosion.

Flow and ignition of hydrogen after discharge were recorded using a digital high-speed camera Photron Fastcam SA1.1. Pictures were taken either directly or using a Schlieren system.

\section{Visualization of hydrogen ignition}

On the basis of the high-speed pictures and signals from the pressure transducers and the photodiode, two modes of the ignition process were identified. In the first mode, called direct ignition, ignition takes place inside the extension tube and flame propagation is observed from the tube up to the main part of the visualization chamber. In that mode, ignition and flame propagation take place shortly after the diaphragm that separates the high-pressure hydrogen container from the tube bursts. In the second mode, called delayed ignition mode, there is a significant delay between the burst of the hydrogen container diaphragm and ignition and subsequent flame propagation; ignition takes place inside the visualization chamber or inside the tube connecting the visualization chamber and the dump tank. Sample test results are presented below.

In Fig. 5, direct high-speed pictures of the various phases are presented in the case of direct ignition, using a $45 \mathrm{~mm}$ long extension tube, with $32 \mathrm{~mm}$ diameter, and 6.2 MPa initial hydrogen pressure. Pressure transducers and photodiode signals courses are shown in Fig. 6 and the test geometry is shown in Fig. 7. The pressure transducers measure overpressure over the initial ambient pressure so that 0 indicates ambient pressure. The left end of the geometry shown in Fig. 7 indicates the location of the diaphragm separating the visualization chamber from the dump tank.

The high-speed pictures clearly show ignition taking place inside the tube. On the courses presented in Fig. 6, a clear correlation is visible between a rise of the signal from the photodiode and the pressure rise inside the visualization chamber. The diaphragm burst corresponds to a rapid decrease in the pressure inside the hydrogen container. There is only a short delay, $<1 \mathrm{~ms}$, between the diaphragm burst and the pressure increase in the visualization chamber, correlating with a signal from the photodiode indicating presence of a 


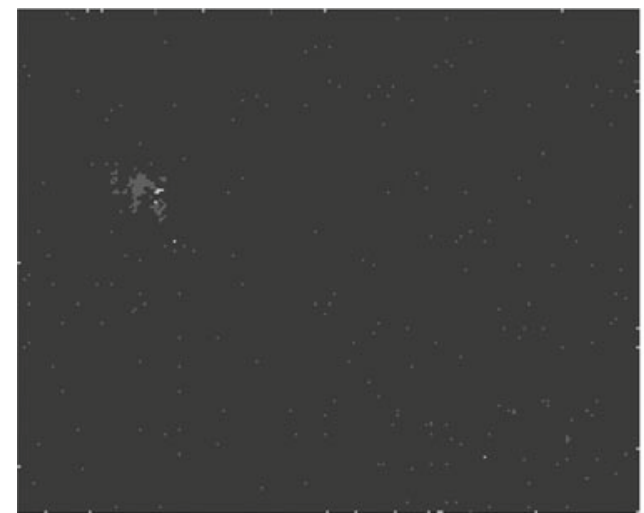

$\mathrm{T}=0 \mathrm{~s}$

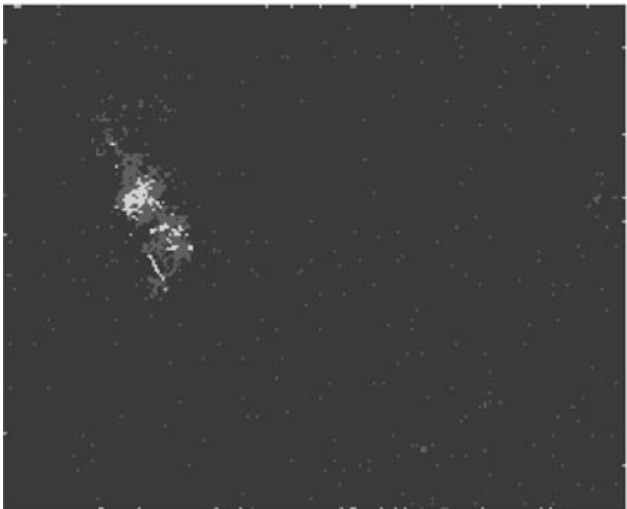

$\mathrm{T}=25 \mu \mathrm{s}$

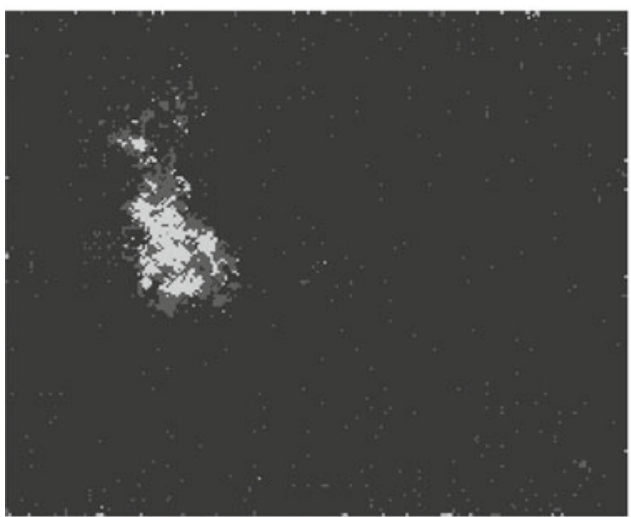

$\mathrm{T}=50 \mu \mathrm{s}$

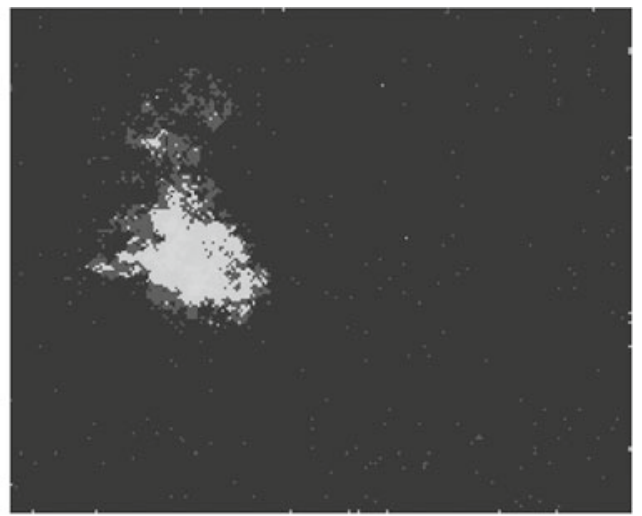

$\mathrm{T}=75 \mu \mathrm{s}$

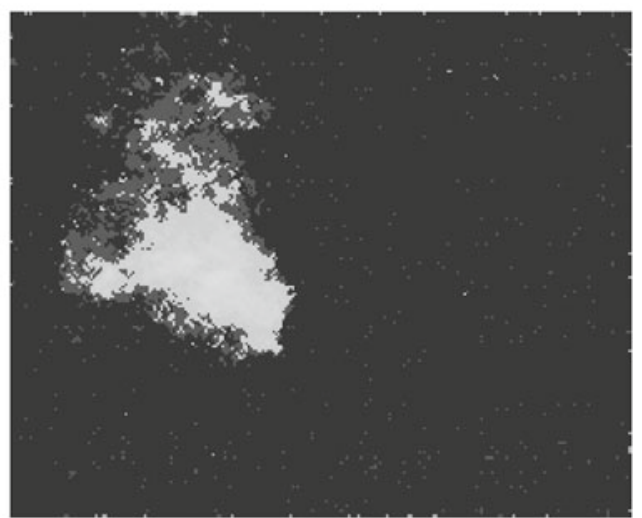

$\mathrm{T}=100 \mu \mathrm{s}$

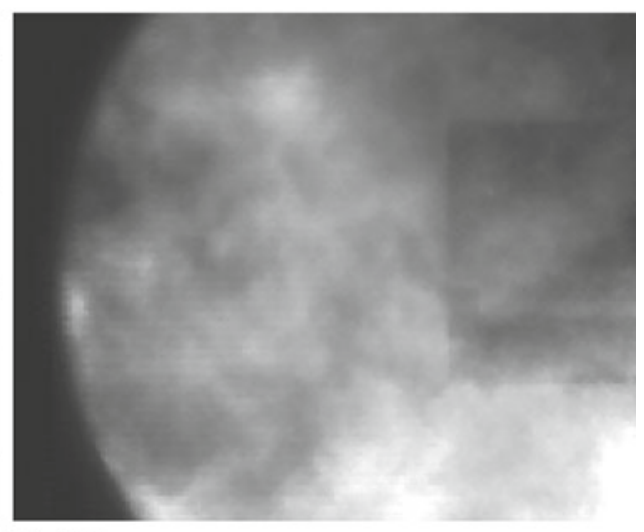

$\mathrm{T}=0.71 \mathrm{~ms}$

Fig. 8 Direct pictures of the hydrogen ignition, extension tube length $95 \mathrm{~mm}$, extension tube diameter $10 \mathrm{~mm}$, initial hydrogen pressure equal to 8.7 MPa. Frame rate 80,000 f/s, shutter $5.5 \mu \mathrm{s}$

flame. Here, ignition took place inside the tube, behind the shock wave generated by the burst of the diaphragm and high-pressure hydrogen release. Ignition followed mixing of expanded hydrogen with air heated by the shock wave.

High-speed pictures presented in Fig. 8 were taken in a test with a $95-\mathrm{mm}$ extension tube length, with $10-\mathrm{mm}$ diameter and $8.7 \mathrm{MPa}$ initial hydrogen pressure. Pressure transducers and photodiode signals are presented in Fig. 9. The test geometry including ignition location is shown in Fig. 10. In this case, ignition took place inside the visualization chamber, some distance away from the end of the extension tube. The pressure and the photodiode signals show that the delay between diaphragm burst and pressure rise inside the visualization chamber is very short, equal to $2 \mathrm{~ms}$. Ignition took place just after diaphragm bursting. This test could be considered to belong in either of the two modes, but because of short time delay it is considered as belonging in the first mode. 


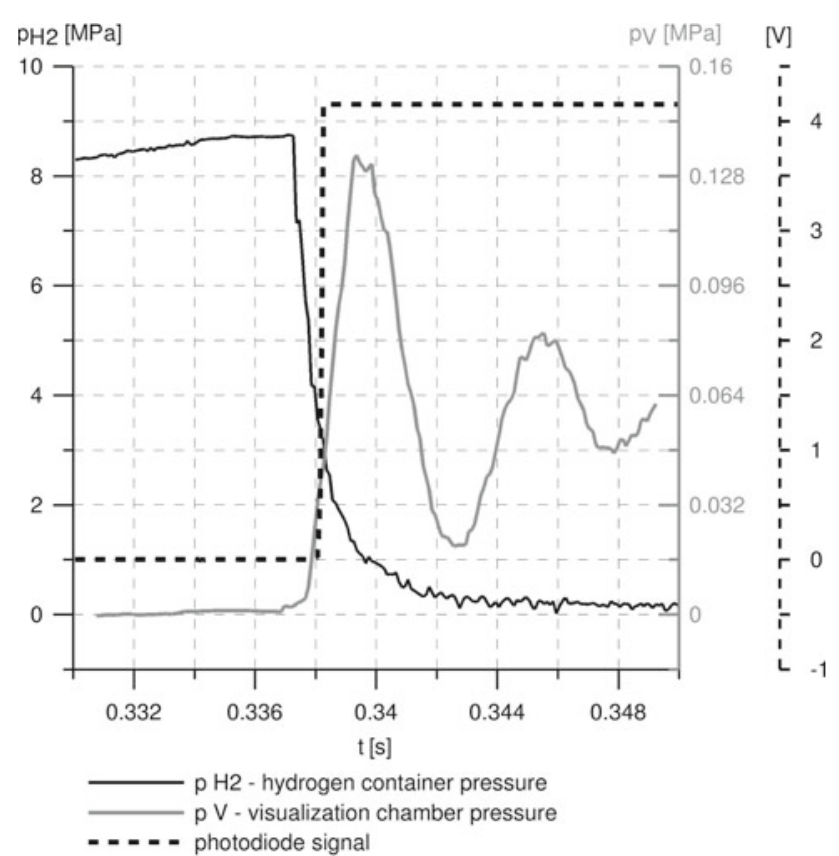

Fig. 9 Pressures and signal from photodiode courses. Extension tube length $95 \mathrm{~mm}$, extension tube diameter $10 \mathrm{~mm}$, initial hydrogen pressure equal to $8.7 \mathrm{MPa}$

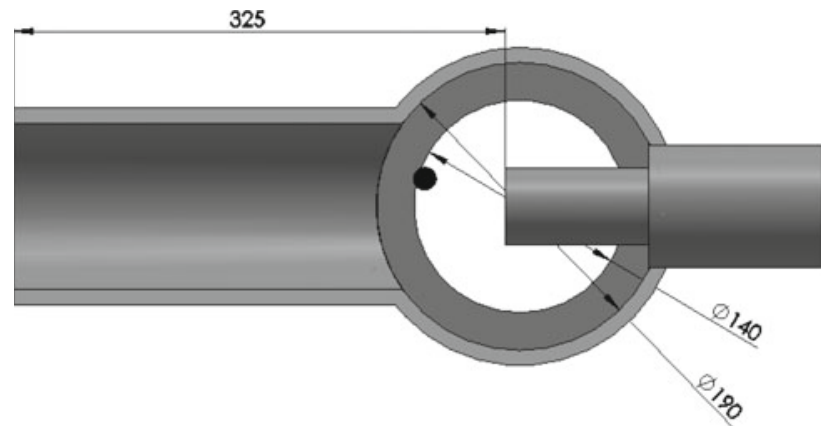

Fig. 10 Geometry of the facility. Extension tube length $95 \mathrm{~mm}$. The black dot indicates location of ignition

The results for a $65-\mathrm{mm}$ long extension tube with $10-\mathrm{mm}$ diameter are presented in Fig. 11, for 7.4-MPa initial hydrogen pressure. Figure 12 presents the pressure transducers and photodiode signals and Fig. 13 shows the geometry. The high-speed pictures show that ignition took place some distance away from the extension tube. The process looks similar to Fig. 8, but a significant difference between these two cases is visible on the pressure transducers and the photodiode signals. In Fig. 12, there is a long delay between a rapid decrease in the pressure inside the hydrogen container and the increase in both the pressure inside the visualization chamber and the photodiode signal. Moreover, pressure decreases inside the visualization chamber after bursting of the hydrogen container diaphragm, which was caused by bursting of the diaphragm that separates the visualization chamber volume from the dump tank. The initial absolute pressure inside the dump tank was lower than $0.03 \mathrm{MPa}$ and the outflow caused a pressure decrease in the visualization chamber, below the initial value. Ignition took place $15 \mathrm{~ms}$ after the hydrogen container diaphragm burst and was probably caused by the additional turbulization generated by bursting of the second diaphragm that separates the visualization chamber from the dump tank.

The pressure wave generated by hydrogen outflow compresses and heats up the air in the extension tube. As a result, chemical reactions between hot air and hydrogen are initiated. However, these reactions did not result in ignition and the flame propagation, probably because hydrogen and hot-air mixing was slow in this case. Burst of the diaphragm separating the visualization chamber from the dump tank generated a strong turbulent flow, resulting in mixing additional fresh air and hydrogen with the mixture already reacting, that was produced earlier inside the tube, which followed the shock moving into the visualization chamber that mechanism caused enhanced the reaction rate, resulting in ignition and flame propagation.

The results are affected by how bursting of the hydrogen container diaphragm takes place. Indeed, the diaphragm bursts in a slightly different way in each individual experiment, generating more or less turbulized high-pressure hydrogen outflow. Whenever mixing inside the tube is much less intense, no ignition takes place inside the tube, but only very limited reaction initiation.

The next set of pictures, presented in Fig. 14, shows results for a $45-\mathrm{mm}$ extension tube length, a $25-\mathrm{mm}$ diameter and 4.8 MPa hydrogen pressure. The pressure transducers and the photodiode signals are presented in Fig. 15, and the geometry is illustrated in Fig. 16.

In this test, ignition took place inside a tube connecting the visualization chamber with the dump tank. The high-speed pictures show a flame propagating from the side of the dump tank back towards the visualization chamber. The ignition delay, of $200 \mathrm{~ms}$, was quite long, as seen on the graphs in Fig. 15, where ignition is indicated by the rapid increase in the visualization chamber pressure and the rise of the signal from the photodiode.

After bursting of the hydrogen container diaphragm, the pressure inside the visualization chamber increases slowly, caused by the hydrogen flowing out from the container to the visualization chamber.

Before ignition occurs, rapid decrease of the visualization chamber pressure is caused by bursting of the diaphragm that separates the visualization chamber from the dump tank. Ignition took place shortly after bursting, under the same mechanism as in the previous case. Comparison of the pressure rise after ignition with the previous cases shows that a longer delay results in a much higher maximum pressure inside the visualization chamber. This is because more hydrogen accumulates inside the visualization chamber. 

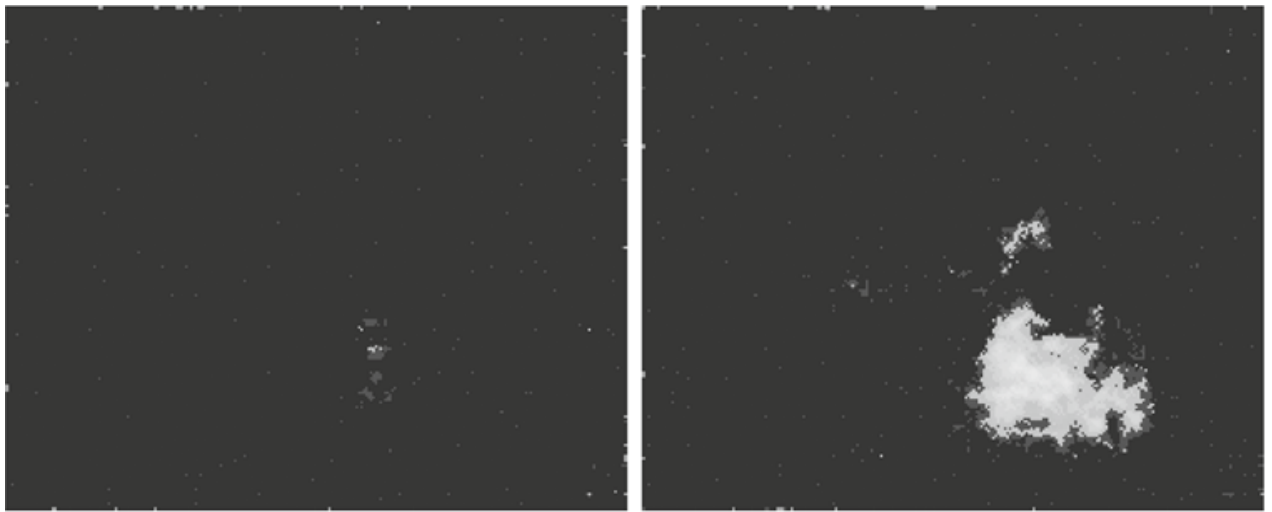

$\mathrm{T}=0 \mathrm{~s}$

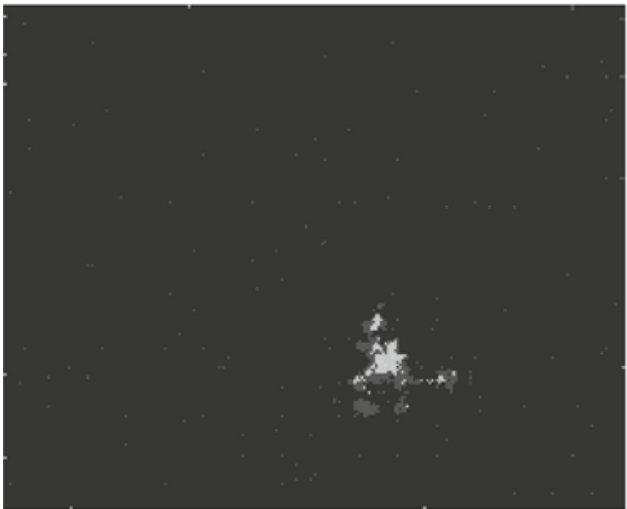

$\mathrm{T}=25 \mu \mathrm{s}$

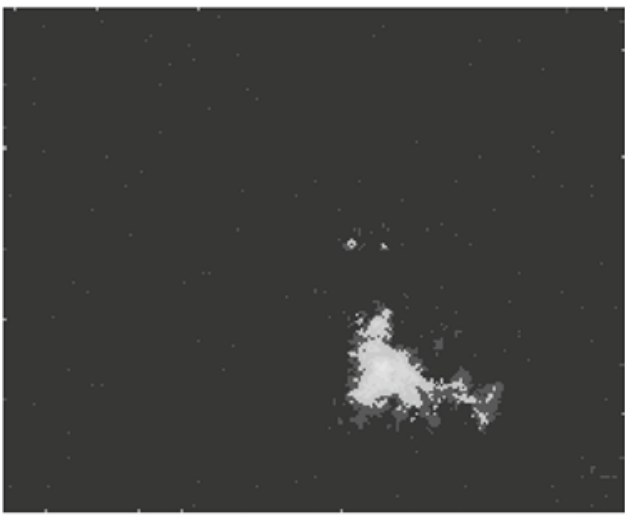

$\mathrm{T}=50 \mu \mathrm{s}$
$\mathrm{T}=75 \mu \mathrm{s}$

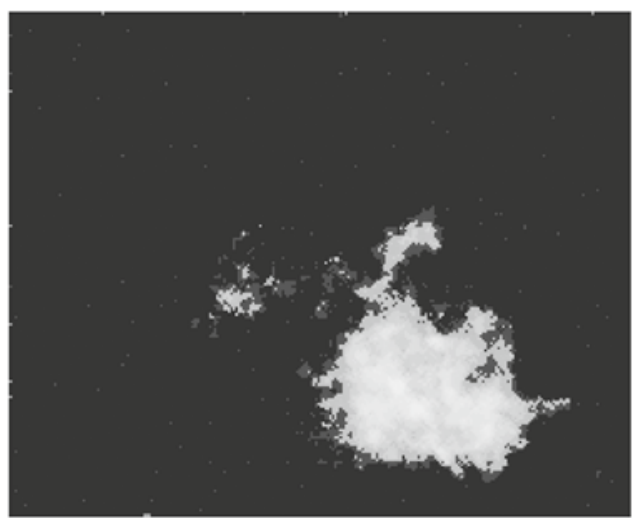

$\mathrm{T}=100 \mu \mathrm{s}$

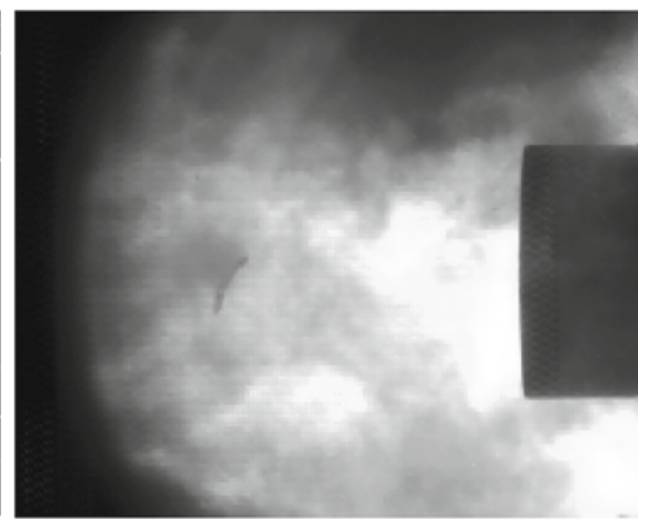

$\mathrm{T}=1.68 \mathrm{~ms}$

Fig. 11 Direct pictures of the hydrogen ignition, extension tube length $65 \mathrm{~mm}$, extension tube diameter $10 \mathrm{~mm}$, initial hydrogen pressure equal to 7.4 MPa. Frame rate 80,000 f/s, shutter $5.5 \mu \mathrm{s}$

Important observations are

- a very long ignition delay time from the beginning of the hydrogen outflow,

- a relatively low initial hydrogen pressure causing ignition, for this extension tube geometry, in comparison with the results obtained by other researchers [4-6].

This suggests that even at a relatively low pressure, a rupture in a hydrogen installation can result in ignition, due to complex processes, including multiple shock reflections and intensive mixing.

\section{Influence of extension tube geometry on critical value of hydrogen pressure and risk of ignition}

A map of the results obtained with the $10-\mathrm{mm}$ extension tube diameter for various lengths is presented in Fig. 17. 


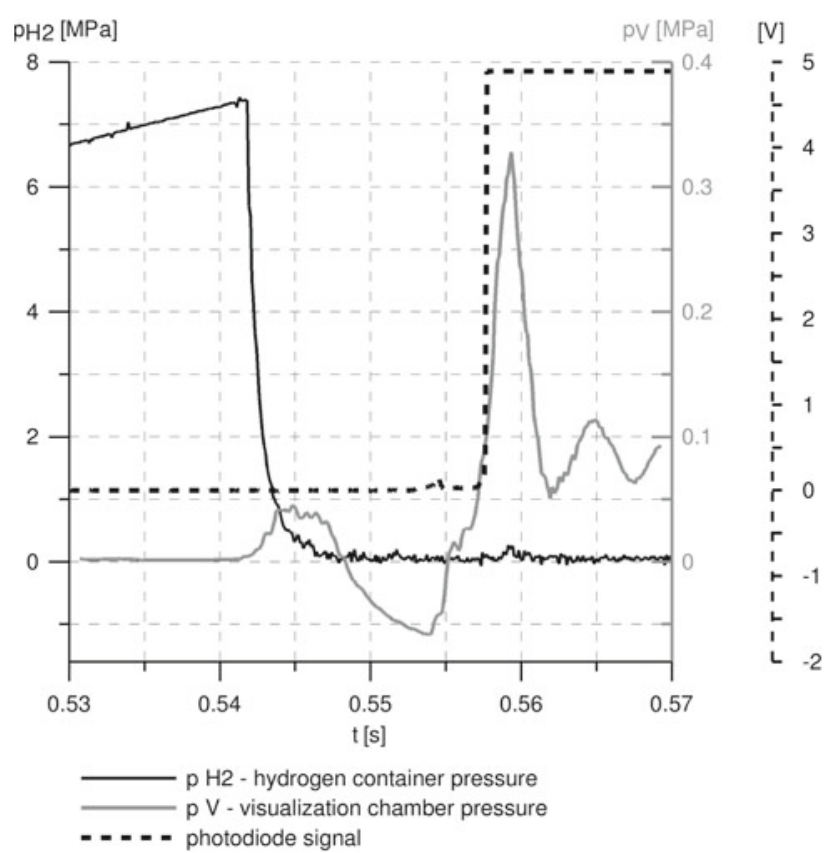

Fig. 12 Pressures and signal from photodiode courses. Extension tube length $65 \mathrm{~mm}$, extension tube diameter $10 \mathrm{~mm}$, initial hydrogen pressure equal to $7.4 \mathrm{MPa}$

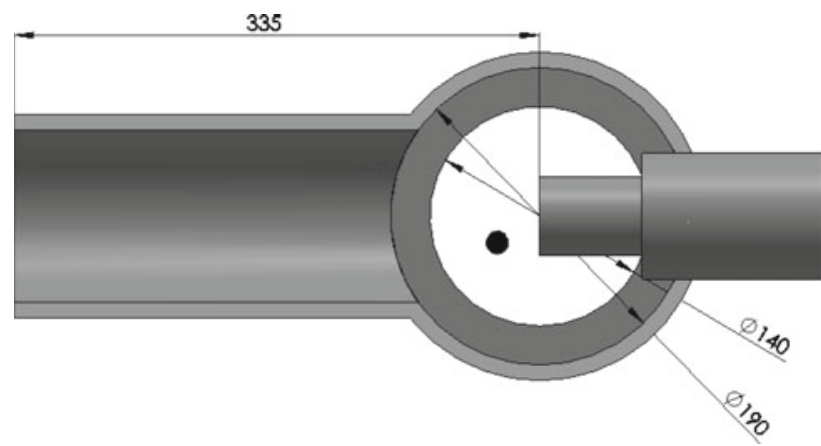

Fig. 13 Geometry of the facility. Extension tube length $65 \mathrm{~mm}$. Black dot indicates location of ignition

A longer tube results in higher repeatability of ignition and in a decrease in the critical pressure required for ignition. For initial hydrogen pressure from 7 to $12 \mathrm{MPa}$ and a $75-\mathrm{mm}$ tube, almost all tests resulted in the ignition. For initial hydrogen pressure in a range between 9 and $13 \mathrm{MPa}$, and a 45-mm length, only about $50 \%$ of the tests resulted in ignition.

The minimum hydrogen pressure required for ignition as a function of the extension tube length, for a 10-mm diameter, is presented in Fig. 18. Changing the length from 65 to $75 \mathrm{~mm}$ resulted in a significant decrease in the critical hydrogen pressure, but above and below these values the tube length has almost no influence on the critical pressure. For two modes presented in Fig. 18, graphs show the critical pressure for direct ignition in the tube and for both direct ignition and delayed ignition. Delayed ignition was observed for a slightly lower initial hydrogen pressure. The difference between these two lines depends on the extension tube length, and is in the range of $1.5-11.5 \%$. When compared with the results by Golub et al. [4] and Mogi et al. [6], the current experiments result in lower critical hydrogen pressure for given extension tube lengths.

Maps of the results for various diameters and a 45 and 95-mm long extension tube are presented in Figs. 19 and 20, respectively. In Fig. 19, for a 45-mm length, the tube diameter has a strong influence on ignition repeatability, but only a small influence on the critical hydrogen pressure. Ignition repeatability decreases significantly as the diameter increases. The critical hydrogen pressure decreases slightly with diameter increase. Thus, in this geometry, the change in the diameter for length of the tube equal to $45 \mathrm{~mm}$ has almost no influence on the critical hydrogen pressure leading to ignition.

The results with the extension tube length $95 \mathrm{~mm}$ and 2 diameters, 10 and $25 \mathrm{~mm}$, differ from those for $45-\mathrm{mm}$ length. In Fig. 20, for 10-mm diameter, most experiments with hydrogen pressure in range 7-12 MPa resulted in ignition, while for $25-\mathrm{mm}$ diameter, only 2 out of 20 experiments resulted in ignition. In both cases, those were delayed ignitions. These results were quite unexpected and further tests should be performed.

For a 10-mm extension tube diameter, ignition repeatability as a function of tube length and hydrogen pressure was investigated, dividing the initial hydrogen pressures into subranges: 5- 7, 7-9, 9-11, 11-13, and 13-15 MPa. Each subrange is identified by its average pressure value: for example, $8 \mathrm{MPa}$ indicates the sub-range 7-9 MPa. Only sub-ranges for which at least three initial hydrogen pressure values were tested, which included in the results below. The percentage of direct and delayed ignition cases was calculated for every sub-range. Percentages of the tests resulting in ignition as a function of extension tube length and hydrogen pressure are presented in Fig. 21. One graph presents the percentage of the tests that resulted in direct ignition and the other one presents the percentage of the tests that resulted in either direct or delayed ignition. Figure 22 indicates the number of tests conducted for different extension tube lengths and different hydrogen pressures.

Only a limited number of tests were performed; ultimately more tests will be required. This analysis performed as a result of an observation made, that ignition, both direct (in the tube) and delayed and was more repeatable for the $75-\mathrm{mm}$ long extension tube than for a 100-mm long tube. Another interesting observation was that ignition proved to be more repeatable for a $45-\mathrm{mm}$ length than for $65 \mathrm{~mm}$. These results can be seen in Fig. 21. The first case considered the 75-mm tube and the initial tests were confirmed that ignition is very repeatable for that length. 

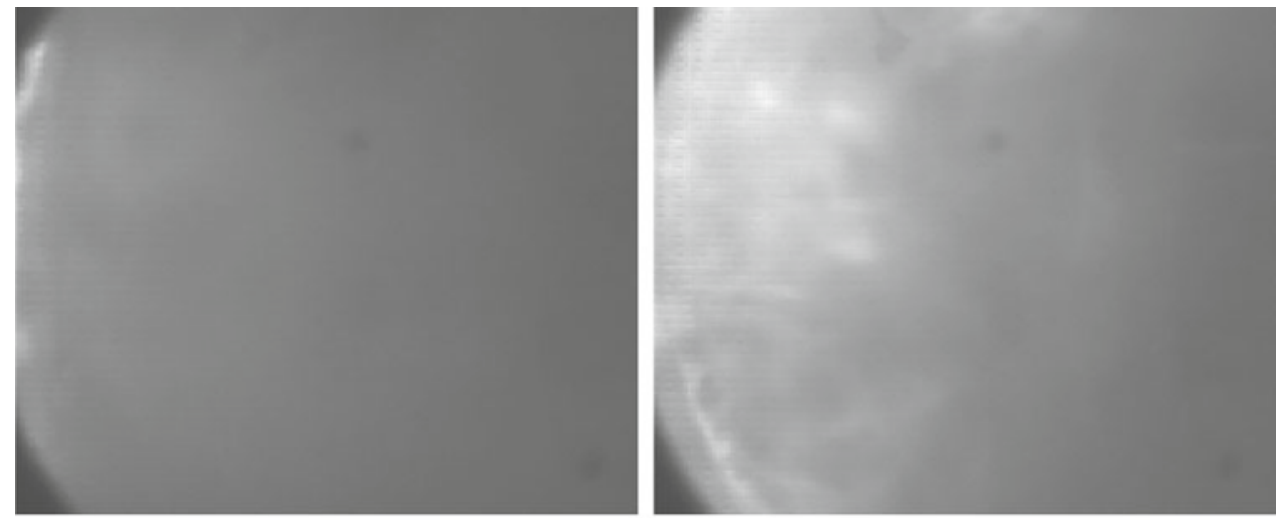

$$
\mathrm{T}=0 \mathrm{~s}
$$

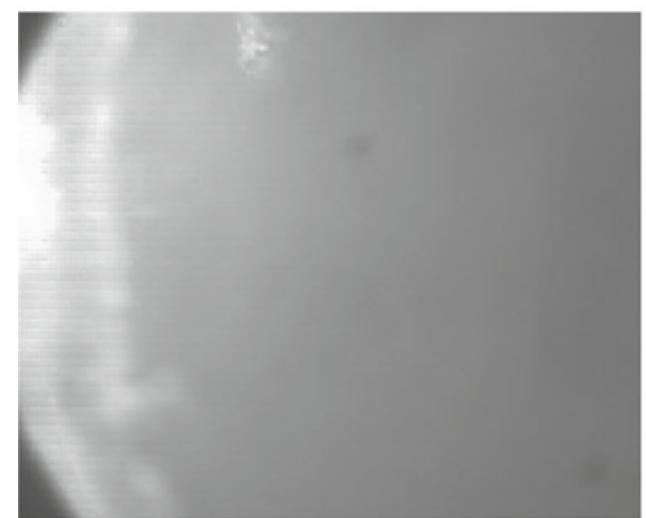

$\mathrm{T}=25 \mu \mathrm{s}$

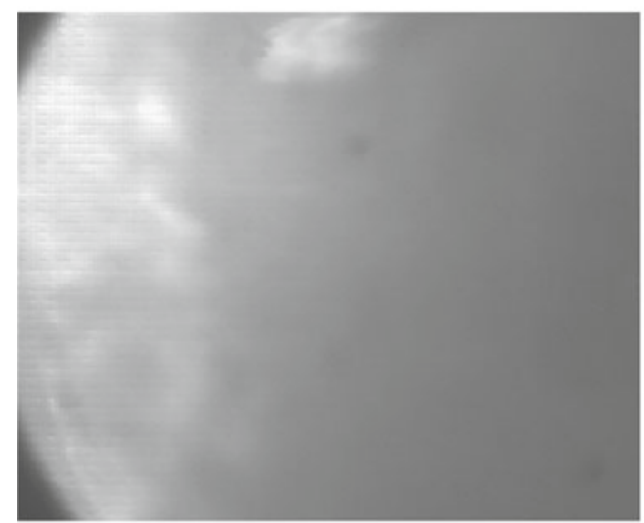

$\mathrm{T}=\mathbf{5 0} \mu \mathrm{s}$
$\mathrm{T}=75 \mu \mathrm{s}$

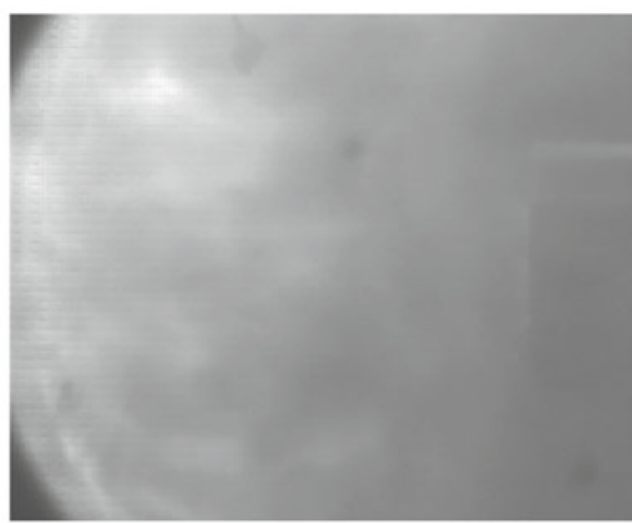

$\mathrm{T}=100 \mu \mathrm{s}$

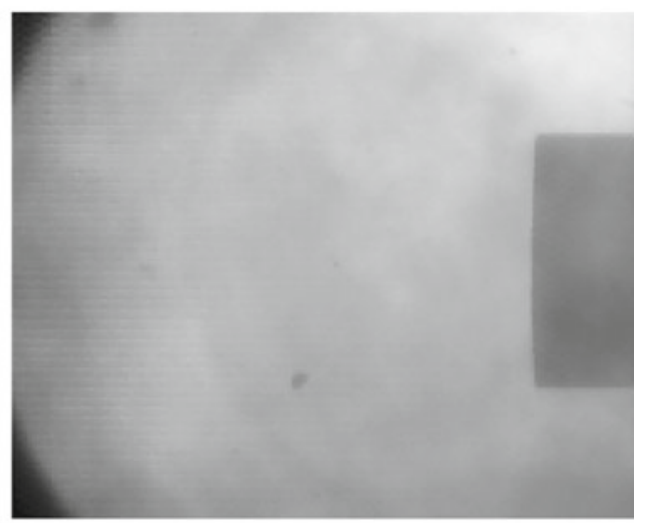

$\mathrm{T}=6.74 \mathrm{~ms}$

Fig. 14 Direct pictures of the hydrogen ignition, extension tube length $45 \mathrm{~mm}$, extension tube diameter $25 \mathrm{~mm}$, initial hydrogen pressure equal to 4.8 MPa. Frame rate 80,000 f/s, shutter $5.5 \mu \mathrm{s}$

The ignition process is affected by precisely how the diaphragm isolating high-pressure hydrogen breaks. The bursting process generates more or less intense turbulence, which has a strong influence on mixing of hydrogen with the air compressed and heated up by the shock wave. Some geometries appear to be less affected by that process, in which case ignition is more independent from the way the diaphragm bursts. This result differs from the literature [4-6], which states that in a longer tube, ignition is more probable at lower hydrogen pressure. This discrepancy will require further research, conducted with several tubes and with various types of diaphragm.

\section{Summary}

The results of experimental research on ignition subsequent to high-pressure hydrogen outflow are presented, 


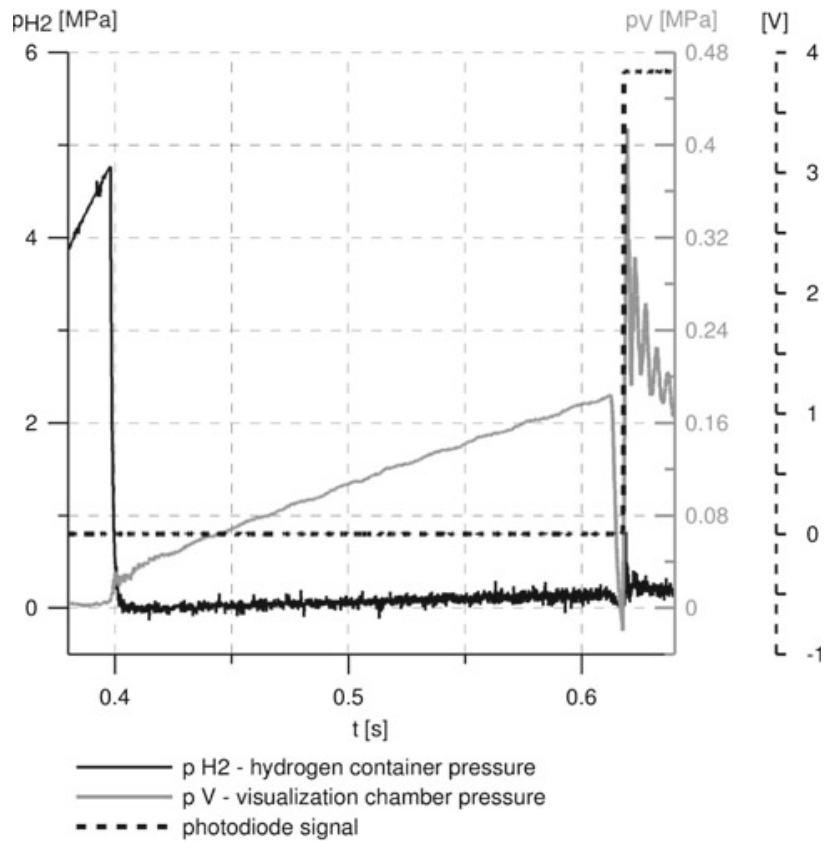

Fig. 15 Pressures and signal from photodiode courses. Extension tube length $45 \mathrm{~mm}$, extension tube diameter $25 \mathrm{~mm}$, initial hydrogen pressure equal to $4.8 \mathrm{MPa}$

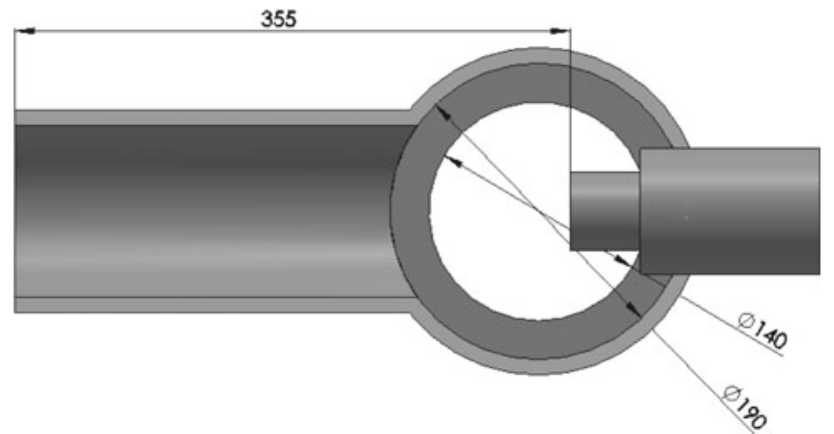

Fig. 16 Geometry of the facility. Extension tube length $45 \mathrm{~mm}$

including high-speed direct pictures leading to the following conclusions

- Hydrogen ignition takes place behind the contact surface that follows the shock wave generated by hydrogen outflow from a high-pressure vessel. Ignition due to mixing of the air heated by the shock wave with expanded hydrogen. Ignition is affected by the bursting process of the diaphragm that isolates the high-pressure hydrogen container.

- Ignition can take place inside the tube directly after bursting of the hydrogen container diaphragm, or, if the high-pressure hydrogen outflow takes place in a confined space, it can be significantly delayed. In a latter case, the delay time can reach hundreds of milliseconds.

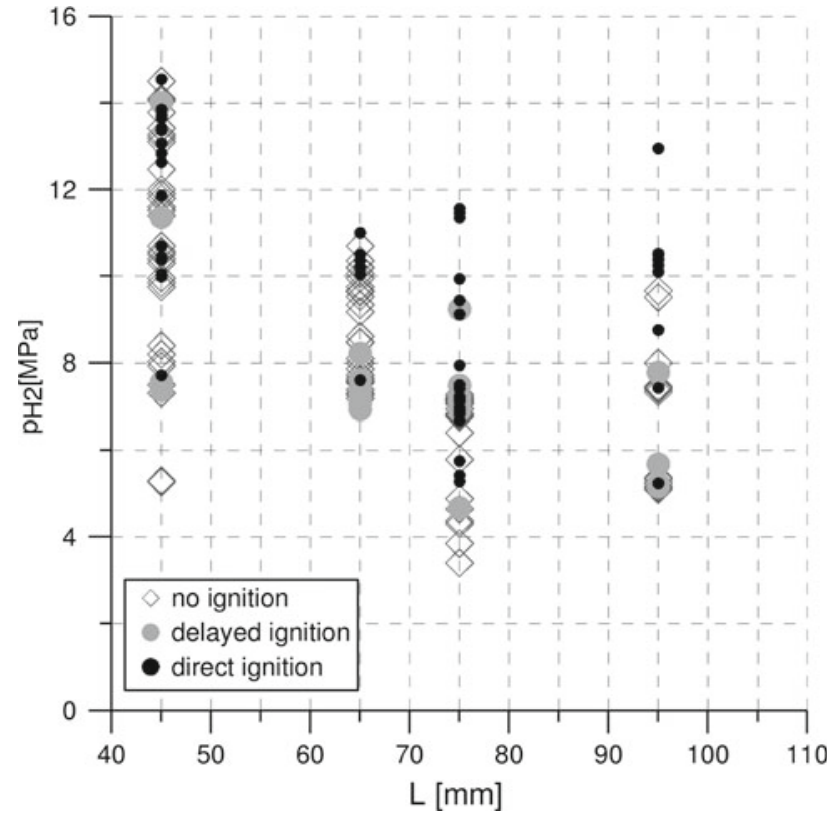

Fig. 17 Results of the experiments as a function of pressure and length of the tube. Tube diameter equal to $10 \mathrm{~mm}$

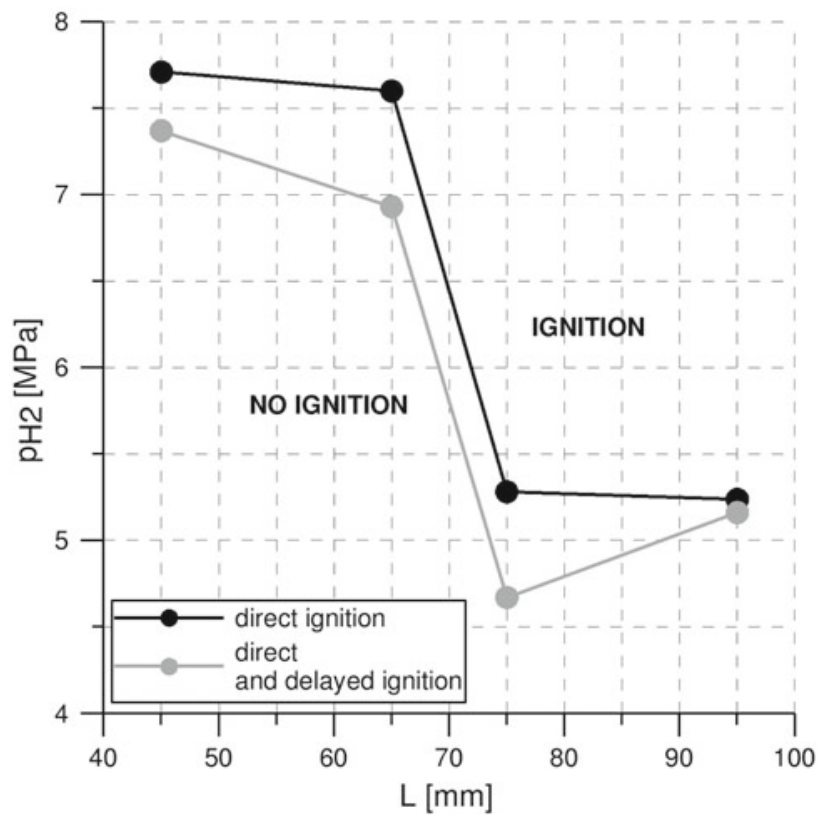

Fig. 18 Critical value of the hydrogen pressure required for ignition as a function of length of the tube. Tube diameter equal to $10 \mathrm{~mm}$

- The extension tube geometry has a significantly effect on the ignition process. For a tube with 10-mm diameter, a longer length results in a lower minimal pressure required for ignition.

- The influence of the extension tube length on ignition repeatability is not monotonic. The results for a $10-\mathrm{mm}$ extension tube diameter suggest that some geometries favor ignition. 


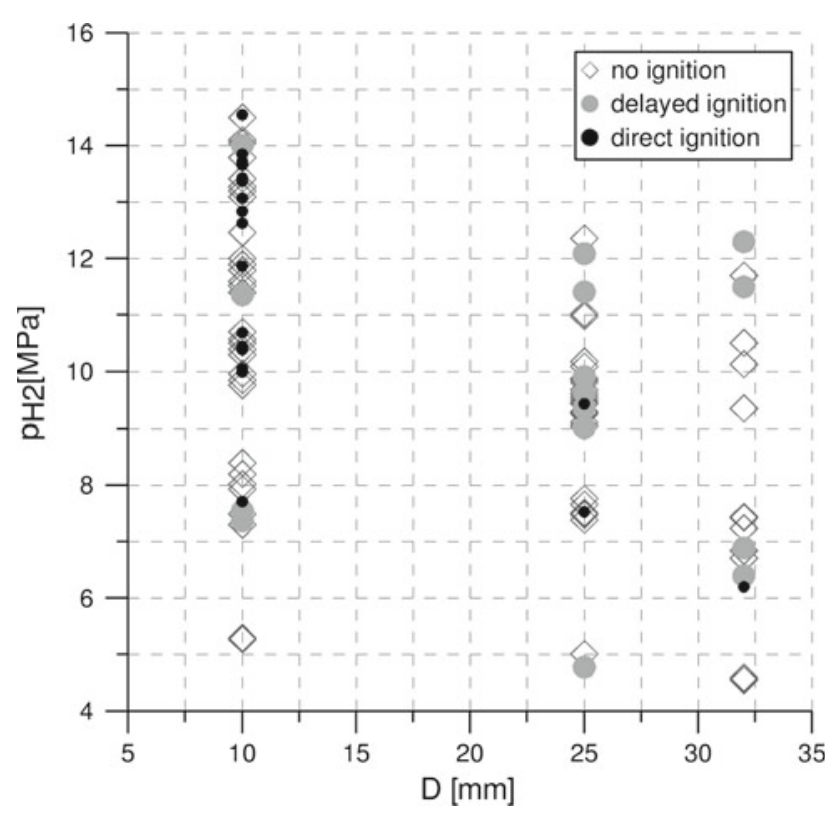

Fig. 19 Results of the experiments as a function of pressure and diameter of the tube. Tube length equal to $45 \mathrm{~mm}$

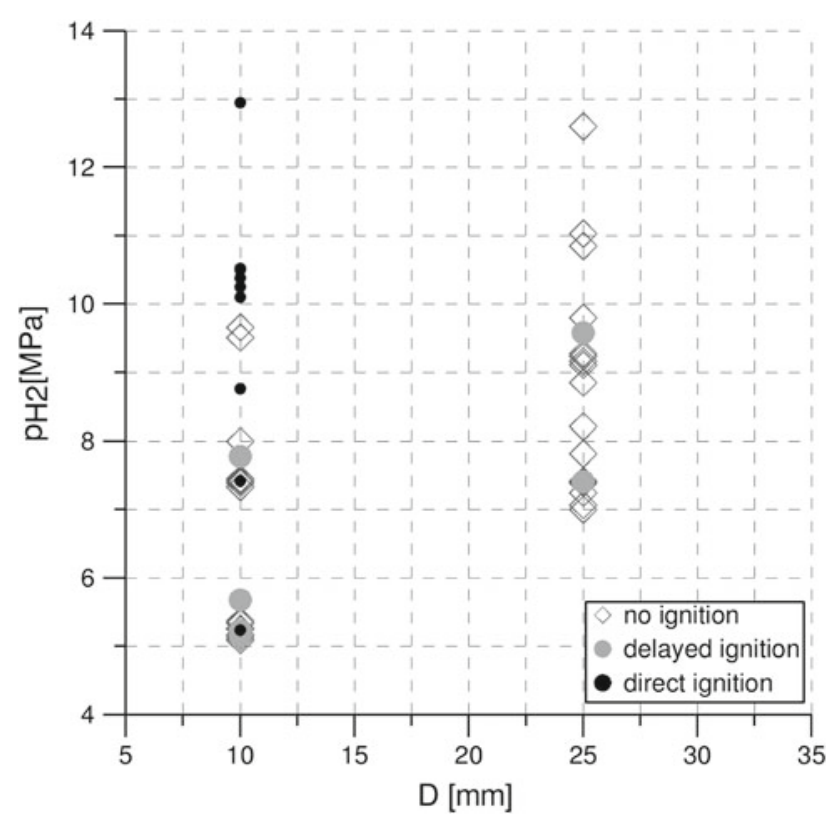

Fig. 20 Results of the experiments as a function of pressure and diameter of the tube. Tube length equal to $95 \mathrm{~mm}$

- The influence of the extension tube diameter depends upon its length.

- For a 45-mm extension tube length, the effect of changing diameter from 10 to $32 \mathrm{~mm}$ on critical hydrogen pressure is insignificant, but ignition repeatability is strongly affected.

- For the 95-mm extension tube length, diameter has a very strong influence on the ignition process. For a $25-\mathrm{mm}$

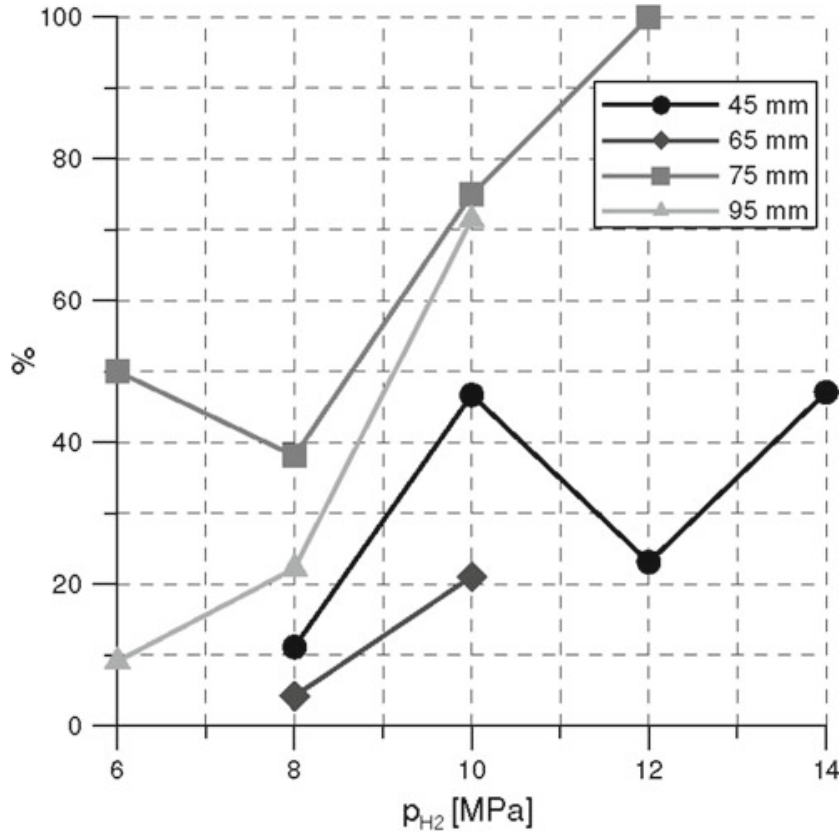

Direct ignitions

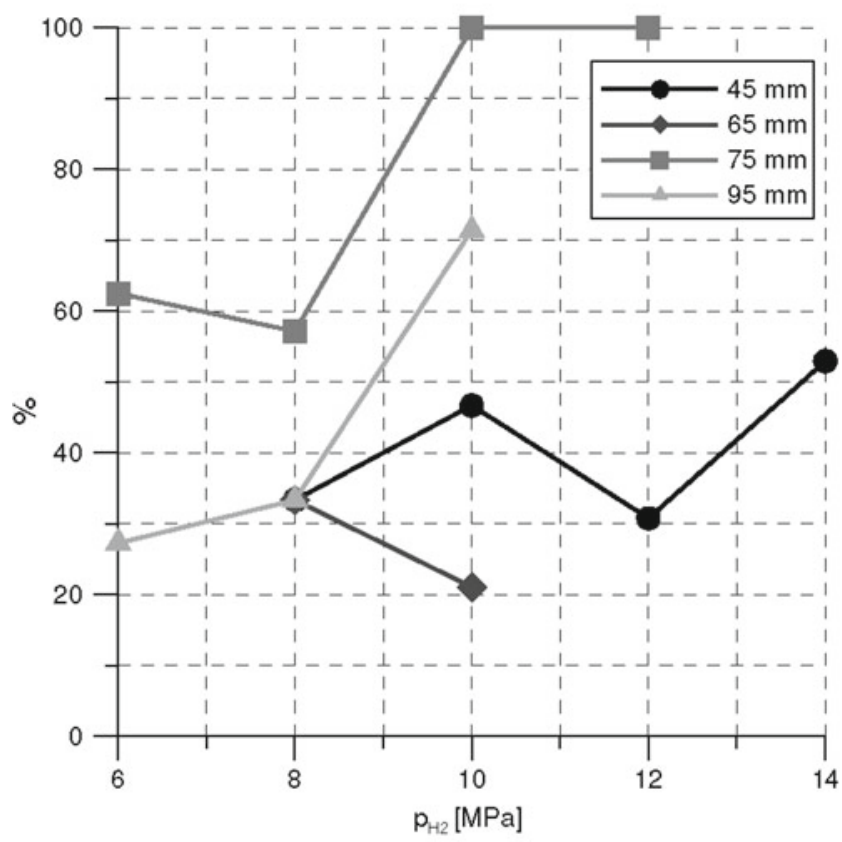

Direct and delayed ignitions

Fig. 21 Percentage of the tests resulted in the hydrogen ignition as a function of the extension tube length and initial hydrogen pressure. Tube diameter equal to $10 \mathrm{~mm}$

diameter, ignition repeatability is much lower than for a 10-mm diameter.

The ignition process shows a stochastic behavior. It appears to depend strongly on the random processes 


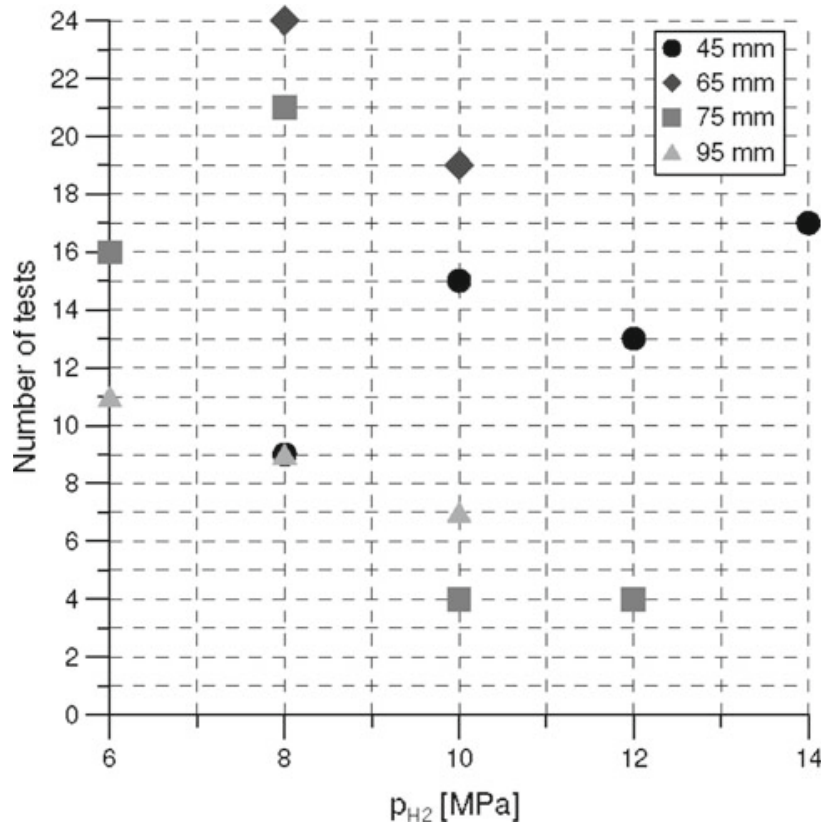

Fig. 22 Number of tests as a function of pressure range and length of the extension tube. Tube diameter $10 \mathrm{~mm}$

associated with diaphragm bursting. This issue requires further research.

Open Access This article is distributed under the terms of the Creative Commons Attribution Noncommercial License which permits any noncommercial use, distribution, and reproduction in any medium, provided the original author(s) and source are credited.

\section{References}

1. Wolanski, P.: Mechanism of synthesis gas explosion during outflow from high pressure installation. Chemik Rok $\mathbf{X X V}(1)$, 23-27 (1972)
2. Wolanski, P., Wojcicki, S.: Investigation into the Mechanism of Diffusion Ignition of a Combustible Gas Flowing into Oxidizing Atmosphere, Fourteenth Symposium (International) on Combustion, pp. 1217-1223. Pittsburgh (1973)

3. Wolanski, P.: Dynamics of Gas Mixtures Ignition, Wydawnictwo Politechniki Warszawskiej (in Polish) (1978)

4. Golub, V.V., Baklanov, D.I., Bazhenova, T.V., Bragin, M.V., Golovastov, S.V., Ivanov, M.F., Volodin, V.V.: Shock-induced ignition of hydrogen gas during accidental or technical opening of highpressure tanks. J. Loss Prev. Process Indus. 20, 439-446 (2007)

5. Golub, V.V.: Diffusion self ignition of sudden discharge of hydrogen. In: Proceedings 7th International Symposium on Hazards, Prevention and Mitigation of Industrial Explosions, Sankt Petersburg, Russia, 7-11 July 2008

6. Mogi, T., Kim, D., Shiina, H., Horiguchi, S.: Self-ignition and explosion during discharge of high-pressure hydrogen. J. Loss Prev. Process Indus. 21, 199-204 (2007)

7. Bond, J.: Sources of Ignition: Flammability Characteristics Of Chemicals and Products. pp. 52 Butterworths-Heinemann Ltd, Oxford (1991)

8. National Research Council: Prudent Practices in the Laboratory: Handling and Disposal of Chemicals, p. 123. National Academy Press, Washington, DC (1995)

9. Edeskuty, F.J., Stewart, W.F.: Safety in the Handling of Cryogenic Fuels. Plenum Publishing Corporation, New York (1996) Chapter 7

10. Liu, Y.-F., Tsaboi, N., Sato, H., Higashino, F., Hayashi, A.K.: Direct numerical simulation on hydrogen fuel jetting from high pressure tank. In: Proceedings of the 20th International Colloquium on the Dynamics of Explosions and Reacting Systems, Montreal, Canada (2005)

11. Liu, Y.-F., Tsaboi, N., Sato, H., Higashino, F., Hayashi, A.K.: Numerical analysis of autoignition in high pressure hydrogen jetting into air. In: Proceedings of the 31th International Symposium on Combustion, Heidelberg, Germany (2006)

12. Dembele, S., Zhang, J., Wen, J.X.: Exploratory study of underexpanded sonic hydrogen jets and jet flames. In: 5 th International Seminar on Fire and Explosion Hazards, Edinburgh, UK (2007) 